\title{
Geospatial analysis of cesarean section in Iran (2016-2020): Exploring clustered patterns and measuring spatial interactions of available health services
}

\author{
Alireza Mohammadi ( $\nabla$ a.mohammadi@uma.ac.ir) \\ University of Mohaghegh Ardabili \\ Elahe Pishgar \\ Shahid Beheshti University \\ Zahra Salari \\ Jahrom University of Medical Sciences \\ Behzad Kiani \\ Mashhad University of Medical Sciences
}

\section{Research Article}

Keywords: Cesarean section, Spatiotemporal analysis, Spatial interaction, Spatial epidemiology, Geographical information systems

Posted Date: February 15th, 2022

DOI: https://doi.org/10.21203/rs.3.rs-1326519/v1

License: (9) This work is licensed under a Creative Commons Attribution 4.0 International License.

Read Full License 


\section{Abstract}

\section{Background}

The lives of babies and mothers are at risk due to the uneven distribution of healthcare facilities required for emergency cesarean sections (CS). However, CS without medical indications might cause complications for mothers and babies, which is a global health problem. Identifying spatiotemporal variations of CS rates in each geographical area could provide helpful information to understand the status of using CS services.

\section{Methods}

This cross-sectional study explored spatiotemporal patterns of CS in the northeast of Iran from 2016 to 2020. Space-time scan statistics and spatial interaction analysis were conducted using geographical information systems to visualize and explore patterns of CS services.

\section{Results}

There were 74,291 CS cases, and the total CS rate was $35.4 \%$ of all deliveries from 2016 until 2020 . Some spatiotemporal clusters regarding CS distribution were identified $(p<0.05)$. According to spatial interaction analysis, there was a solid spatial concentration of hospital facilities in the political center of the study area. Moreover, a high degree of inequity was observed in spatial accessibility to CS hospitals in the whole study area.

\section{Conclusions}

A high CS rate in comparison to the global CS rate was observed. Therefore, healthcare policymakers might investigate the study area for potential reasons for the remarkable difference. Hospital capacity and distance from population centers to hospitals play an essential role in CS rate variations and spatial interactions among people and CS facilities. As a result, some healthcare strategies, e.g., building new hospitals and empowering the existing local hospitals to perform CS in areas out of service, might be developed to decline inequity.

\section{Background}

Cesarean section (CS) is performed through a surgical incision of the abdomen and uterus of females to deliver a baby. It is a common and essential operation if any complication arises for mother and baby during pregnancy or natural childbirth (1). Consequently, CS is often a life-saving intervention for mothers and babies (2). According to the World Health Organization (WHO), CS should cover $10 \%$ to $15 \%$ of all deliveries at most $(3,4)$. However, the worldwide CS rate increased from $6.7 \%$ in 1990 to $21 \%$ in 2021, with $14.3 \%$ growth (3), and spatial variations in CS distribution are observed in different geographical areas $(5,6)$. 
The determinants of choosing CS for delivery are multifaceted and complex. Some CS have medical indications due to mothers' and babies' health conditions (e.g., mothers' obesity or premature birth) and mothers' previous experiences $(7,8)$. Moreover, recent studies have shown that socioeconomic status (e.g., household income) could be associated with CS on maternal request (2,9-12). Furthermore, spatial accessibility to CS-related healthcare facilities might play a significant role in CS choice (13-15). On the other hand, if CS has a medical indication, lack of access to adequate facilities for CS is a threat to the lives of mothers and babies (8).

The recent scientific literature on why CS is the preferred delivery method could be summarized in four categories. The first group focused on the compulsory causes of CS. They include fear of labor, anxiety for fetal injury/death, doctor's suggestion, previous infertility, anxiety for gynecologic examination, emotional aspects $(7,8)$, mother's age, body mass index and her health condition, time of birth, any experience of prior bad delivery, the weight of baby, pathological placenta, severe bleeding during childbirth, wound infection, hematoma, intestinal obstruction (16) and abnormal prenatal situation (1722).

The second group of studies focused on socioeconomic factors (e.g., household income, residence address as town or village, education level, and mother's age at the time of marriage) (10,23-26). For instance, Feng et al. (23) showed that the CS rate in urban areas was three times more than in rural areas, and economic condition was one of the most contributing factors in choosing CS rather than natural childbirth. Some studies as the third group focused on the importance of accessibility to CS-related facilities in choosing the type of delivery (13-15). For instance, Kumar et al. (15) showed that with a 1-km increase in distance from an individual's place to the nearest medical center for CS operation, the probability of choosing CS is declined by 4.4 times. Also, Kesterton et al. (14) showed a $32 \%$ increase in referrals to a hospital for CS with each 5-km closer to the hospital. Emily et al. (8) revealed that CS rates increased in Uganda, and there was geographical heterogeneity in CS rates and inequality in CS-related health facilities.

The fourth group of studies used geographical and spatial analysis to explain and interpret CS rates $(6,19)$. For instance, Vanderlaan et al. (6) in Georgia identified counties with high-rate CS clusters had significantly lower access to midwives. Furthermore, more deliveries were paid by Medicaid in these counties, and a higher proportion of births for women belonging to racial/ethnic minority groups were more likely to be rural. In another study in Ethiopia, Tegegne et al. (27) showed that CS rates were clustered in areas with a high percentage of urbanization and the highest available medical facilities (e.g., the country's capital). In another study in Norway, Mannseth et al. (28) showed that high-risk deliveries were concentrated in large hospitals with better services and equipment that were not evenly distributed in different country regions. Consequently, this affected the CS rates spatial distribution.

Despite Iran having one of the highest CS rates globally as 47.9\% in 2018 (29), to our knowledge, no study in the country has examined potential geographical variations of CS with a spatiotemporal approach. Therefore, this study aims to analyze the temporal, spatial, and spatiotemporal patterns of CS 
in northeastern Iran. This study also attempts to visualize available medical services for CS considering distance and service area approaches.

\section{Methods}

\section{Study region}

Khorasan-Razavi Province (KRP) is located in North-East Iran at latitude $35.1020^{\circ}$ North, longitude $59.1042^{\circ}$ East (Fig. 1). KRP covers an area of $119 \mathrm{~km}^{2}$, and its population was about $6,435,000$ in 2015, of which $75 \%$ were located in urban areas. There were 18 public hospitals in the study area (Fig.1). In Iran, counties are used as the basic unit of socio-economic and health studies, and most statistics are gathered at this level. Furthermore, most health services are concentrated in counties' main centers. Therefore, pregnant women living in villages or cities refer to these main centers. There were 30 counties in the study region and, we used county level as the scale for spatial analysis.

\section{Datasets}

The data were obtained from Mashhad University of Medical Sciences, which collects and stores information on pregnancy and births in the study area. The data included 74,291 CS from 1 January 2016 to 31 December 2020 gathered from 18 public hospitals performing CS. Incomplete and invalid data (123 CS cases) were excluded from analyses. To consider participants' privacy, all personal information of individuals was removed from the records. Information such as age, residence address, hospital name, and admission dates was used. All spatial data layers were projected to WGS 1984 UTM Zone $40 \mathrm{~N}$ system.

\section{Data analysis}

\section{Empirical Bayesian Smoothed (EBS) rates}

An Empirical Bayes Smoothing (EBS) approach was used to calculate the spatially smoothed rate of CS deliveries. The relevant number of women of childbearing age varies across areas under investigation, so the precision of raw CS rate varies as well (30). This variance instability requires smoothing, and we used the local EBS technique to reduce the random fluctuations due to the population size of women of childbearing age $(31,32)$. To calculate the local EBS CS rate for each county, we considered the number of CS deliveries as the event variable and the total number of all women of childbearing age as the population field.

\section{CS rates visualization}


Choropleth maps represented the EBS CS rates by eight rate classes varying from Low: 65 to high: $\geq$ 13,553 per 100,000 women at childbearing age.

\section{Global spatial autocorrelation}

We used Global Moran's Index (GMI) to measure spatial dependency since it is generally more accurate concerning spatial autocorrelation than other metrics $(33,34)$. The "contiguity edges corners" method was used to model spatial relationships, which is suitable for polygon type complications (35). The average distance band value was calculated as $80.74 \mathrm{~km}$ as the basis of calculations. Although GMI statistics is a powerful way to indicate spatial autocorrelation, this method alone cannot identify hidden spatiotemporal patterns and clusters of CS rates over time (36). To address this limitation, local spatial and spatiotemporal statistics were also used as follows.

\section{Spatiotemporal methods}

The Scan statistics methodology includes purely temporal analysis, purely spatial analysis, spatiotemporal analysis, and spatiotemporal variation in temporal trends. The methods can detect clusters irrespective of any predefined geographical boundaries in predefined study time (37). In this study, the retrospective Poisson probability model as a discrete type of scan statistic was used to analyze the rates of CS deliveries in the study region from 2016 through 2020. Time aggregation length was set to 1 year, and the maximum window size of analysis was adjusted to $50 \%$ as a percent of the women of childbearing age in the study region and study time. The null hypothesis of no clusters was rejected at the simulated $p \leq 0.05$ for the primary (most likely) clusters, and 999 Monte Carlo replications were performed for statistical inference. Statistical details of the results of these methods are given in Tables 1 to 3 of Appendix file 1.

\section{Interaction analysis}

Spatial interaction is the degree of linkage between two locations, the origin and the destination (38). In this study, we used two methods to detect and analyze the spatial interactions among counties centroids (origins) and hospitals (destinations) based on simplified steps of the gravity model in the geographical information system (GIS) environment. The purpose of using these analyses was to identify hospitals' potential "sphere of influence" and then explore the actual spatial interactions among counties as origins and hospitals as service facilities.

In the first step, Thiessen polygon and closest facility methods were applied in QGIS to determine the potential "spheres of influence" for each hospital concerning each county. The hypothesis was that women in each county would go to the nearest CS provider.

In the second step, we calculated the gravity intensity for each county using Equation 1: 


\section{CS gravity intensity $=\frac{C S \text { rate }_{i, j}}{\sum C S \text { rate }_{i, j}} \times 1$}

Where; CS rate $i, j$, is the rate of CS per 100 hospital staff as its capacity in the county $i$ at hospital $j$. The result is a normalized value between 0 and 1 . Finally, we used the gravity weighted line density method to visualize the interaction hotspots. This method calculates a magnitude-per-unit area from polyline features that fall within a radius around each cell. The Kernel Density Estimation (KDE) method shows critical, dense, or high-value areas (39). In this study, we used the KDE method to show the density of Gravity Intensity flows (interactions) between the origin (population-weighted counties centroids) and destination (hospitals). Each county's Gravity Intensity weighted flow lines (hub distance lines) were specified as weight fields in the KDE method. In this study, the KDE method was also used to show health facilities' spatial concentration in the study area (Fig. A).

\section{Software}

All scan statistics analyses were conducted using SatScan software (developed by Martin Kulldorff and Information Management Services Inc. Cambridge, Massachusetts, 1997). QGIS software version 3.20, a free and open-source GIS software, was used to visualize the choropleth maps and GeoDa 10.8 to calculate EBS rates.

\section{Results}

\section{Descriptive analysis}

During the study time, from the total 209,935 deliveries performed in public hospitals of KRP, 74,291 deliveries were done by CS (35.39\% of the total). The average age of mothers was 32.33 years in CS time, but the age followed some geographical variations (Fig. 2). For example, the highest average age was in Joghatai (36 years), and the lowest average was in Firouzeh county (29.20 years). Among the five age groups (15-19, 20-24, 25-29, 30-34, and >35 years) of mothers who had a CS experience, the highest portion of CS (37.64\%) was observed in the age group of 35 years and older. The lowest CS rate (1.48\%) was related to the age group of 15 to 19 years.

According to figure 3 , out of 30 counties, 11 (36.7\%) counties experienced high rates (mean $=4,670$ and $S D=4553$ per 100,000 women of childbearing age). The rate of CS decreased from 862 per 100,000 women in 2016 to 844 per 100,000 women in 2020. However, the mean rate of CS was higher in 2017 (1,079 per 100,000 women of childbearing age) among the other years. These results confirmed that 
most counties with high rates (> 5,000 per 100,000 women of childbearing age) were in the east, southeast, and west.

\section{Purely temporal and spatial clusters}

Figure 4A indicates that high-rate time clusters of total CS were predominantly distributed $(O E=1.18$, $R R=1.34, L L R=799.97, p<0.05)$ between 2017 and 2018. Global Moran's / statistics for CS deliveries based on EBS rates (Moran's $1=0.247$, $z$-score $=2.46, p<0.05$ ) revealed that the spatial autocorrelation was significant, and the null hypothesis was rejected as CS incidence rates were spatially clustered (Fig. 4B). Figure 5 shows the purely spatial pattern of CS incidence rates based on the Poisson probability model of scan statistics. Five most likely clusters $(R R>1, p<0.05)$ (hot spots) were identified that were distributed heterogeneously in the study region, and 14 of the 30 counties were located in these 5 clusters.

\section{Spatiotemporal clusters}

The study region's statistically significant high-rate CS spatiotemporal clusters were mainly south to north (Fig. 6). Based on the $50 \%$ maximum window size, altogether 13 locations (counties) were classified as high-rate areas in different time periods $(R R>1, p<0.05)$ (Fig. 6). For example, cluster one formed from 2017 to 2018 in the southeast, while cluster three was in the north between 2016 and 2017.

\section{Spatial variation in temporal trends}

According to figure 7, two high-trend CS clusters were found. These clusters included the counties with the highest variations compared to counties inside and outside. The first cluster formed in the north, and the second cluster stood in the southeast of the study area. In the first cluster, one location was in hightrend statistically significant clusters $(\mathrm{LRR}=453.01, \mathrm{RR}=1.11, p$-value $<0.05)$. In the second cluster, there were eight statistically significant high-trend clusters $(\operatorname{LRR}=31.76, \mathrm{RR}=1.43, p$-value $<0.05)$. It is clear that CS rates were increasing overall, but not in the same way in all areas. For example, cluster one experienced an average annual growth of $61.3 \%$, but this growth was $3.56 \%$ in cluster two.

\section{Interaction analysis}

Figure $8 \mathrm{~A}$ shows the optimum distance from the origin (counties centroids) to destination (hospitals) based on closest facility and Thiessen polygons methods. The Thiessen polygons boundaries indicate the estimated coverage of the service area of each hospital according to its capacity. The hub-distance (shown as red lines) indicates the Euclidean linear travel distance (in $\mathrm{km}$ ) from each county centroid (origin) to the nearest hospital (destination). Ideally, people in each county should go to the nearest hospital for CS. The mean optimal was determined as $48.41 \pm 36.2 \mathrm{~km}$ (Fig. 8A). The maps show a significant difference between the assumption of optimal access (Fig.8A) and the actual flows (Fig.8B) 
regarding access to the CS facilities. The actual mean distance is about $153.7 \pm 152.4 \mathrm{~km}$, three times more than the optimal distance to access CS-related hospitals.

Figure 9A shows the capacity (number of staff) weighted heat map of hospital care facilities (intensity per sq. $\mathrm{km}$ ) as CS service providers in the study region. The dark color and low range vales $(<0.001$ per sq. $\mathrm{km}$ ) show the low-density areas in this map. Bright yellow color with a high range value $(>0.005$ per sq. km) indicates high-density areas (hotspots) and are located in northeast Mashhad County (the capital of the province). The figure indicates spatial inequality in the distribution of hospital care facilities. Global Moran's I showed the positive spatial autocorrelation to clarify the findings, which indicates a strongly clustered pattern and unequal allocation of CS hospitals in the study region. Figure 9B shows the result of the gravity model as a heat map, according to this map, the same areas form hotspots (light-yellow areas) in CS interaction flows. For example, hospitals 4, 10, 13, 14, and 18 located in Mashhad County with high normalized gravity intensity values $(\mathrm{Gl}>0.02)$.

The gravity model shows that the intensity of linkages and the capacity of hospitals (Fig.8A) have a profound effect on the CS flows in the study region. We performed the Pearson test between CS rates and hospital capacities to prove this. Test results showed a strong significant correlation at the 0.01 level $(r=.726$ and $p .<0.05)$ as a strong relationship between CS rates and hospital capacity. For example, hospital 1 with a capacity of 3,518 personnel located in the hotspot area. The gravity model only reveals the linkages and importance of the facility capacity in the interactions and does not clarify the role of distance in the interaction between origin and destination. The distance between origins and destinations was measured using the hub-distance lines method to respond to this limitation. Figure 10 shows the distance between origins and destinations in $\mathrm{km}$. According to the analysis, the mean distance between county centers and hospitals in the entire study region was $153.7 \mathrm{~km}$. The results show that most hospitals located in the hotspot areas have a shorter mean distance to county centroids (mean distance $<153.7 \mathrm{~km}$ ). For example, hospitals $3,4,13,14,17$, and 18, were at an average distance less than $139.32 \mathrm{~km}$ from the county (population centers) centroids. With more investigation on the gravity model results, the Pearson test was used in two steps. In the first step, the relationship between the gravity intensity of each county centroid and the closest hospital was measured. The test results showed a significant, strong, and inverse correlation (Sig. $<0.05, r=-.604$ ). Therefore, the CS rates increased in the destination facility when distance decreased. In the second step, the same test was applied to measure the association among distance between entire county centroids (origins) GI and all hospital care facilities (destinations). The test results show that the correlation was significant and inverse but not strong (Sig.<0.05, Pearson test value $=-.17$ ). It can be concluded that close distance has a direct effect on increasing spatial interactions.

\section{Discussion}

The present study provided a spatiotemporal analysis of CS rates in northeastern Iran between 2016 and 2020. The findings of this study showed that although the rate of CS is lower (35.39\%) than the national average (47.9\%) (29), it is higher than the global average (21\%) (3) and the recommended rate of the 
WHO (10\%-15\%) (1,2,4). Previous studies have confirmed similar results regarding the high rate of CS in Iran $(40,41)$. The CS rate in this study is only for CS performed in public hospitals, while considering the number of CS in private hospitals might cause a higher rate (41). CS rates have fluctuated in the geographical areas of the study region at the study time and have decreased in comparison to the start point of the study time in 2016. This decrease can have several reasons; Some studies have highlighted the effect of fear of COVID-19 infection on reducing CS on maternal request (42). Furthermore, some researchers have noted that the implementation of governmental CS restriction guidelines since 2015 in Iran has reduced the rate of CS in public hospitals in recent years (40). The results of our study showed that the average age of mothers who used CS was 32.33 years, which confirms the results of previous studies showing that CS rates increase with age $(12,17,19,20)$.

Our results based on purely spatial analysis of EBS rates showed significant differences among diverse counties regarding CS rates, which led to spatial heterogeneity in the distribution of CS rates in the study region and study time. Moreover, Global Moran's I autocorrelation test results confirmed the existence of spatial dependency in the study area. We also identified the space-time and spatial variations in temporal trends clusters of CS EBS rates in the study area based on space-time scan statistics. Our analysis also showed significant spatial rate variations among the clusters, as reported in previous studies $(27,43)$.

The interaction analysis results showed that, firstly, in terms of accessibility to CS facilities, there is a clear difference between the optimum situation (Fig.8A) and the existing condition (Fig. 8B) in the study region. Furthermore, the results of spatial density analysis of hospital facilities have shown that hospital care services have been significantly concentrated in particular areas of the study region and have followed a wholly clustered pattern (spatial dependence). This means an unequal distribution of hospital services care for CS deliveries in the study region (Fig.9a). Similar studies have shown the same problem in most developing countries (8). The highest number of referrals for CS was to hospitals concentrated in particular areas (southeast of RKP). With the increase in the capacity of hospitals, the rate of CS in those hospitals is increased. Previous studies have also confirmed that the rate of CS increases in wellequipped and high-capacity hospitals $(27,28,44)$.

Our findings show that in addition to the importance of spatial accumulation and the capacity of hospitals, accessibility (distance) also has a very significant role in spatial interactions between medical service providers and CS requests in the study region. With decreasing distance from hospitals, CS rate and the number of CS performed in those hospitals increased. In other words, most CS has been referred to the nearest hospital. Although most CS flows appear to be northeast (Mashhad County), based on the hub-distance and Pearson test results, hospitals in the hotspot area (Fig.9A) have also provided better physical accessibility to county centers (origins) compared to other hospitals (Fig.10). Previous studies have also shown that CS rates in nearby hospitals have increased as the distance between hospitals and the place of residence of pregnant women has decreased $(14,15,43)$. For example, Harrison and Goldenberg showed that long distances to health facilities and poor transport systems had been documented as barriers to obtaining CS (45). 


\section{Limitation and future studies}

We collected and analysed CS data from public hospitals and did not have private hospitals' data. The second limitation was that socio-economic indicators (such as household income, employment, and unemployment status) at the county level are not provided in Iran. Access to these indicators could help us examine the relationship between CS rates and socio-economic indicators that is recommended for future studies.

\section{Conclusions}

The present study vividly depicts the temporal, spatial, and spatiotemporal patterns of CS, with heterogeneous spatial patterns in the study region. We showed that integrating scan statistics with GIS visualization techniques is feasible to identify spatiotemporal patterns of CS. The approach can be generalized to other geographical areas. Although the CS generally decreased during the last years in the study region, the rates are still higher than the world average. Our results can assist policymakers in implementing more targeted interventions for CS control and resource allocation in the most in-need areas. The present study reinforces the need for integrated prevention and control strategies of the unnecessary CS in the study region and regional policymakers might take long-term measures to decrease the CS through public awareness. Finally, sometimes CS is unintended and urgent; Therefore, equitable distribution of hospitals and reallocation of healthcare facilities is inevitable in the long-term in the study region.

\section{Abbreviations}

CS: Caesarean section

WHO: World Health Organization,

EBS: Empirical Bayesian Smoothed

GMI: Global Moran's Index

GIS: geographical information system

KDE: Kernel Density Estimation

OE: Observed/Expected

RR: Relative risk

LLR: Log Likelihood ratio

Gl: Gravity intensity 


\section{Declarations}

\section{Ethics approval and consent to participate}

This study has been approved by the Ethical Committee of Mashhad University of Medical Sciences (reference number= IR.MUMS.MEDICAL.REC.1399.571). The data were aggregated at the county level. All experiments were performed according to relevant guidelines and regulations. No individual data was used and due to the retrospective nature of the study, informed consent was waived by the regional committee on ethics in biomedical research of Mashhad University of Medical Sciences.

\section{Consent to publish}

Not applicable.

\section{Availability of data and materials}

All the data used in this study is publicly available via supplementary file 1.

\section{Competing interests}

The authors declare that they have no competing interests.

\section{Funding}

This study received funding from Mashhad University of Medical Sciences (number= 4000573) and University of Mohaghegh Ardabili (number= 991523).

\section{Contributions}

Conceptualization: AM and BK; Methodology: AM; Formal analysis: AM; Geocoding and cleaning: ZS and EP; Writing: AM, EP and BK; Review and editing: BK; Supervision: AM and BK; All authors read and approved the final version of the manuscript for submission.

\section{Acknowledgements}

We would like to thank Mashhad University of Medical Sciences and University of Mohaghegh Ardabili for funding this study. 


\section{References}

1. Dadipoor S, Madani A, Alavi A, Roozbeh N, Safari Moradabadi A. A survey of the growing trend of caesarian section in Iran and the world: a review article. Iran J Obstet Gynecol Infertil. 2016 Sep 22;19(27):8-17. Available from: https://ijogi.mums.ac.ir/article_7847.html DOI:10.22038/IJOGI.2016.7847

2. Konlan KD, Baku EK, Japiong M, Dodam Konlan K, Amoah RM. Reasons for Women's Choice of Elective Caesarian Section in Duayaw Nkwanta Hospital. J Pregnancy. 2019;2019. Available from: https://pubmed.ncbi.nlm.nih.gov/31360548/ DOI:10.1155/2019/2320743

3. Caesarean section rates continue to rise, amid growing inequalities in access [Internet]. [cited 2022 Jan 28]. Available from: https://www.who.int/news/item/16-06-2021-caesarean-section-ratescontinue-to-rise-amid-growing-inequalities-in-access

4. Chien P. Global rising rates of caesarean sections. BJOG An Int J Obstet Gynaecol. 2021 Apr 1;128(5):781-2. Available from: https://onlinelibrary.wiley.com/doi/full/10.1111/1471-0528.16666 DOI:10.1111/1471-0528.16666

5. Da Silva Campi SF, Nascimento LFC. Spatial distribution of C-sections within the state of São Paulo. Rev Assoc Med Bras. 2014 Sep 1;60(5):419-23. Available from: http://www.scielo.br/j/ramb/a/vkpLLMxxSJ4QBnrXHcbWfMM/?lang=en DOI:10.1590/18069282.60.05.008

6. Vanderlaan J, Edwards JA, Dunlop A. Geospatial variation in caesarean delivery. Nurs Open. 2020 Mar 1;7(2):627. Available from: /pmc/articles/PMC7024620/ DOI:10.1002/NOP2.433

7. O'Donovan $\mathrm{C}, \mathrm{O}$ 'Donovan $\mathrm{J}$. Why do women request an elective cesarean delivery for non-medical reasons? A systematic review of the qualitative literature. Birth. 2018 Jun 1;45(2):109-19. Available from: https://pubmed.ncbi.nlm.nih.gov/29105822/ DOI:10.1111/BIRT.12319

8. Atuheire EB, Opio DN, Kadobera D, Ario AR, Matovu JKB, Harris J, et al. Spatial and temporal trends of cesarean deliveries in Uganda: 2012-2016. BMC Pregnancy Childbirth. 2019 Apr 16;19(1):1-8. Available from: https://bmcpregnancychildbirth.biomedcentral.com/articles/10.1186/s12884-0192279-6 DOI:10.1186/S12884-019-2279-6/FIGURES/2

9. Jenabi E, Khazaei S, Bashirian S, Aghababaei S, Matinnia N. Reasons for elective cesarean section on maternal request: a systematic review. J Matern Fetal Neonatal Med. 2020 Nov 16;33(22):386772. Available from: https://pubmed.ncbi.nlm.nih.gov/30810436/ DOI:10.1080/14767058.2019.1587407

10. Faisal-Cury A, Menezes PR, Quayle J, Santiago K, Matijasevich A. The relationship between indicators of socioeconomic status and cesarean section in public hospitals. Rev Saude Publica. 2017 Mar 23;51(0):14. Available from: https://pubmed.ncbi.nlm.nih.gov/28355336/ DOI:10.1590/S1518-8787.2017051006134

11. Uno K, Mayama M, Yoshihara M, Takeda T, Tano S, Suzuki T, et al. Reasons for previous Cesarean deliveries impact a woman's independent decision of delivery mode and the success of trial of labor 
after Cesarean. BMC Pregnancy Childbirth. 2020 Mar 24;20(1):1-8. Available from: https://bmcpregnancychildbirth.biomedcentral.com/articles/10.1186/s12884-020-2833-2 DOI:10.1186/S12884-020-2833-2/TABLES/5

12. Elnakib S, Abdel-Tawab N, Orbay D, Hassanein N. Medical and non-medical reasons for cesarean section delivery in Egypt: a hospital-based retrospective study. BMC Pregnancy Childbirth. 2019 Nov 8;19(1). Available from: https://pubmed.ncbi.nlm.nih.gov/31703638/ DOI:10.1186/S12884-0192558-2

13. Sarma S. Demand for outpatient healthcare. Appl Heal Econ Heal Policy 2009 74. 2012 Aug 6;7(4):265-77. Available from: https://link.springer.com/article/10.1007/BF03256160 DOI:10.1007/BF03256160

14. Kesterton AJ, Cleland J, Sloggett A, Ronsmans C. Institutional delivery in rural India: The relative importance of accessibility and economic status. BMC Pregnancy Childbirth. 2010 Jun 6;10(1):1-9. Available from: https://bmcpregnancychildbirth.biomedcentral.com/articles/10.1186/1471-2393-1030 DOI:10.1186/1471-2393-10-30/FIGURES/2

15. Kumar S, Dansereau EA, Murray CJL. Does distance matter for institutional delivery in rural India? http://dx.doi.org/101080/000368462014950836. 2014 Nov 15;46(33):4091-103. Available from: https://www.tandfonline.com/doi/abs/10.1080/00036846.2014.950836 DOI:10.1080/00036846.2014.950836

16. Da Silva Charvalho P, Hansson Bittár M, Vladic Stjernholm Y. Indications for increase in caesarean delivery. Reprod Health. 2019 May 30;16(1):1-6. Available from: https://reproductive-healthjournal.biomedcentral.com/articles/10.1186/s12978-019-0723-8 D0I:10.1186/S12978-019-07238/TABLES/3

17. Acharya K, Paudel YR, Health A, Chandra S, Dhungana M. Rising trends and persisting inequalities in cesarean section rates in Nepal: evidence from demographic and health surveys 2006-2016. 2020 Apr 22; Available from: https://www.researchsquare.com DOI:10.21203/RS.3.RS-15560/V2

18. Kim AM, Park JH, Kang S, Yoon TH, Kim Y. An ecological study of geographic variation and factors associated with cesarean section rates in South Korea. BMC Pregnancy Childbirth. 2019 May 9;19(1):1-8. Available from: https://bmcpregnancychildbirth.biomedcentral.com/articles/10.1186/s12884-019-2300-0 DOI:10.1186/S12884-019-2300-0/TABLES/2

19. Srivastava S, Chaurasia H, Kumar Singh KJ, Chaudhary P. Exploring the spatial patterns of cesarean section delivery in India: Evidence from National Family Health Survey-4. Clin Epidemiol Glob Heal. 2020 Jun 1;8(2):414-22. Available from: http://cegh.net/article/S2213398419303835/fulltext DOI:10.1016/J.CEGH.2019.09.012

20. Smith GCS, Cordeaux Y, White IR, Pasupathy D, Missfelder-Lobos H, Pell JP, et al. The effect of delaying childbirth on primary cesarean section rates. PLoS Med. 2008 Jul;5(7):1123-32. Available from: https://pubmed.ncbi.nIm.nih.gov/18597550/ DOI:10.1371/JOURNAL.PMED.0050144 
21. Benli AR, Benli NC, Usta AT, Atakul T, Koroglu M. Effect of Maternal Age on Pregnancy Outcome and Cesarean Delivery Rate. J Clin Med Res. 2015;7(2):97. Available from: /pmc/articles/PMC4245060/ DOI:10.14740/JOCMR1904W

22. Ecker JL, Chen KT, Cohen AP, Riley LE, Lieberman ES. Increased risk of cesarean delivery with advancing maternal age: indications and associated factors in nulliparous women. Am J Obstet Gynecol. 2001;185(4):883-7. Available from: https://pubmed.ncbi.nlm.nih.gov/11641671/ DOI:10.1067/MOB.2001.117364

23. Feng $X L$, Xu L, Guo Y, Ronsmans $C$. Factors influencing rising caesarean section rates in China between 1988 and 2008. Bull World Health Organ. 2012 Jan 1;90(1). Available from: https://pubmed.ncbi.nlm.nih.gov/22271962/ DOI:10.2471/BLT.11.090399

24. Guilmoto CZ, Dumont A. Trends, Regional Variations, and Socioeconomic Disparities in Cesarean Births in India, 2010-2016. JAMA Netw Open. 2019 Mar 1;2(3):e190526-e190526. Available from: https://jamanetwork.com/journals/jamanetworkopen/fullarticle/2728617 DOI:10.1001/JAMANETWORKOPEN.2019.0526

25. Zhang J, Troendle J, Reddy UM, Laughon SK, Branch DW, Burkman R, et al. Contemporary cesarean delivery practice in the United States. Am J Obstet Gynecol. 2010;203(4):326.e1-326.e10. Available from: https://pubmed.ncbi.nlm.nih.gov/20708166/ DOI:10.1016/J.AJOG.2010.06.058

26. Ayalew M, Mengistie B, Dheressa M, Demis A. Magnitude of Cesarean Section Delivery and Its Associated Factors Among Mothers Who Gave Birth at Public Hospitals in Northern Ethiopia: Institution-Based Cross-Sectional Study. J Multidiscip Healthc. 2020;13:1563. Available from: /pmc/articles/PMC7678705/ DOI:10.2147/JMDH.S277747

27. Kassaw TEGEGNE T, Chojenta C, Smith R, Loxton D, Kassaw Tegegne T, Getachew T. Caesarean Delivery Use in Ethiopia: A Spatial and Hierarchical Bayesian Analysis. 2021 Jun 7; Available from: https://www.researchsquare.com DOI:10.21203/RS.3.RS-572537/V1

28. Mannseth J, Berentsen GD, Skaug HJ, Lie RT, Moster D. Variation in use of Caesarean section in Norway: An application of spatio-temporal Gaussian random fields. Scand J Public Health. 2021 Dec 1;49(8):891-8. Available from: https://pubmed.ncbi.nlm.nih.gov/33938301/ DOI:10.1177/14034948211008579

29. Shirzad M, Shakibazadeh E, Hajimiri K, Betran AP, Jahanfar S, Bohren MA, et al. Prevalence of and reasons for women's, family members', and health professionals' preferences for cesarean section in Iran: a mixed-methods systematic review. Reprod Health. 2021 Dec 1;18(1). Available from: https://pubmed.ncbi.nlm.nih.gov/33388072/ DOI:10.1186/S12978-020-01047-X

30. Elliott $P$, Wartenberg D. Spatial Epidemiology: Current Approaches and Future Challenges. Environ Health Perspect. 2004;112(9):998. Available from: /pmc/articles/PMC1247193/ DOI:10.1289/EHP.6735

31. Marshall RJ. Mapping Disease and Mortality Rates Using Empirical Bayes Estimators. Appl Stat. 1991;40(2):283. DOI:10.2307/2347593 
32. Manton KG, Woodbury MA, Stallard E, Riggan WB, Creason JP, Pellom AC. Empirical Bayes procedures for stabilizing maps of U.S. cancer mortality rates. J Am Stat Assoc. 1989;84(407):63750. Available from: https://pubmed.ncbi.nlm.nih.gov/12155378/ DOI:10.1080/01621459.1989.10478816

33. Anselin L. Local Indicators of Spatial Association-LISA. Geogr Anal. 1995 Apr 1;27(2):93-115. Available from: https://onlinelibrary.wiley.com/doi/full/10.1111/j.1538-4632.1995.tb00338.x DOI:10.1111/J.1538-4632.1995.TB00338.X

34. Dubé J, Legros D. Spatial econometrics using microdata. Available from: https://www.wiley.com/engb/Spatial+Econometrics+using+Microdata-p-9781119008651

35. Mitchell A. ESRI Guide to GIS Analysis, Volume 2: Spatial Measurements and Statistics. $2005 ; 252$. Available from: http://books.google.com/books?id=sdSTIwEACAAJ\&pgis=1

36. Kiani B, Raouf Rahmati A, Bergquist R, Hashtarkhani S, Firouraghi N, Bagheri N, et al. Spatio-temporal epidemiology of the tuberculosis incidence rate in Iran 2008 to 2018. BMC Public Health. 2021 Dec 1;21(1):1-20. Available from: https://bmcpublichealth.biomedcentral.com/articles/10.1186/s12889021-11157-1 DOI:10.1186/S12889-021-11157-1/FIGURES/8

37. Kulldorff M. SaTScan TM User Guide SaTScan User Guide v10.0. 2021; Available from: http://www.satscan.org/

38. Thomas A, Aryal J. Spatial analysis methods and practice: describe-explore-explain through GIS. J Spat Sci. 2021 Sep 2;66(3):533-4. DOI:10.1080/14498596.2021.1955816

39. Ceyhan E, Ertuğay K, Düzgün Ş. Exploratory and inferential methods for spatio-temporal analysis of residential fire clustering in urban areas. Fire Saf J. 2013 May 1;58:226-39.

DOI:10.1016/J.FIRESAF.2013.01.024

40. Azami-Aghdash S, Ghojazadeh M, Dehdilani N, Mohammadi M, Asl Amin Abad R. Prevalence and Causes of Cesarean Section in Iran: Systematic Review and Meta-Analysis. Iran J Public Health. 2014;43(5):545. Available from: /pmc/articles/PMC4449402/

41. Badiee S, Ravanshad Y, Azarfar A, Dastfan F, Babayi S, Mirzayi N. Survey of Cesarean Deliveries and Their Causes in Hospitals Affiliated to Mashhad University of Medical Sciences, Iran, 2011. Iran J Obstet Gynecol Infertil. 2013 Aug 23;16(66):10-7. Available from: https://ijogi.mums.ac.ir/article_1899.html DOI:10.22038/IJOGI.2013.1899

42. Ranjbar F, Allahqoli L, Ahmadi S, Mousavi R, Gharacheh M, Eshraghi N, et al. Changes in pregnancy outcomes during the COVID-19 lockdown in Iran. BMC Pregnancy Childbirth. 2021 Dec 1;21(1):1-6. Available from: https://bmcpregnancychildbirth.biomedcentral.com/articles/10.1186/s12884-02104050-7 DOI:10.1186/S12884-021-04050-7/TABLES/2

43. Phibbs CS, Mark DH, Luft HS, Peltzman-Rennie DJ, Garnick DW, Lichtenberg E, et al. Choice of hospital for delivery: a comparison of high-risk and low-risk women. Health Serv Res. 1993 Jun;28(2):201-22. Available from: /pmc/articles/PMC1069930/?report=abstract

44. Baicker K, Buckles KS, Chandra A. Geographic variation in the appropriate use of cesarean delivery. Health Aff (Millwood). 2006;25(5). Available from: https://pubmed.ncbi.nlm.nih.gov/16895942/ 
DOI:10.1377/HLTHAFF.25.W355

45. Harrison MS, Goldenberg RL. Cesarean section in sub-Saharan Africa. Matern Heal Neonatol Perinatol 2016 21. 2016 Jul 8;2(1):1-10. Available from: https://mhnpjournal.biomedcentral.com/articles/10.1186/s40748-016-0033-x DOI:10.1186/S40748016-0033-X.

\section{Figures}

\section{The map of counties of Razavi-Khorasan Province}

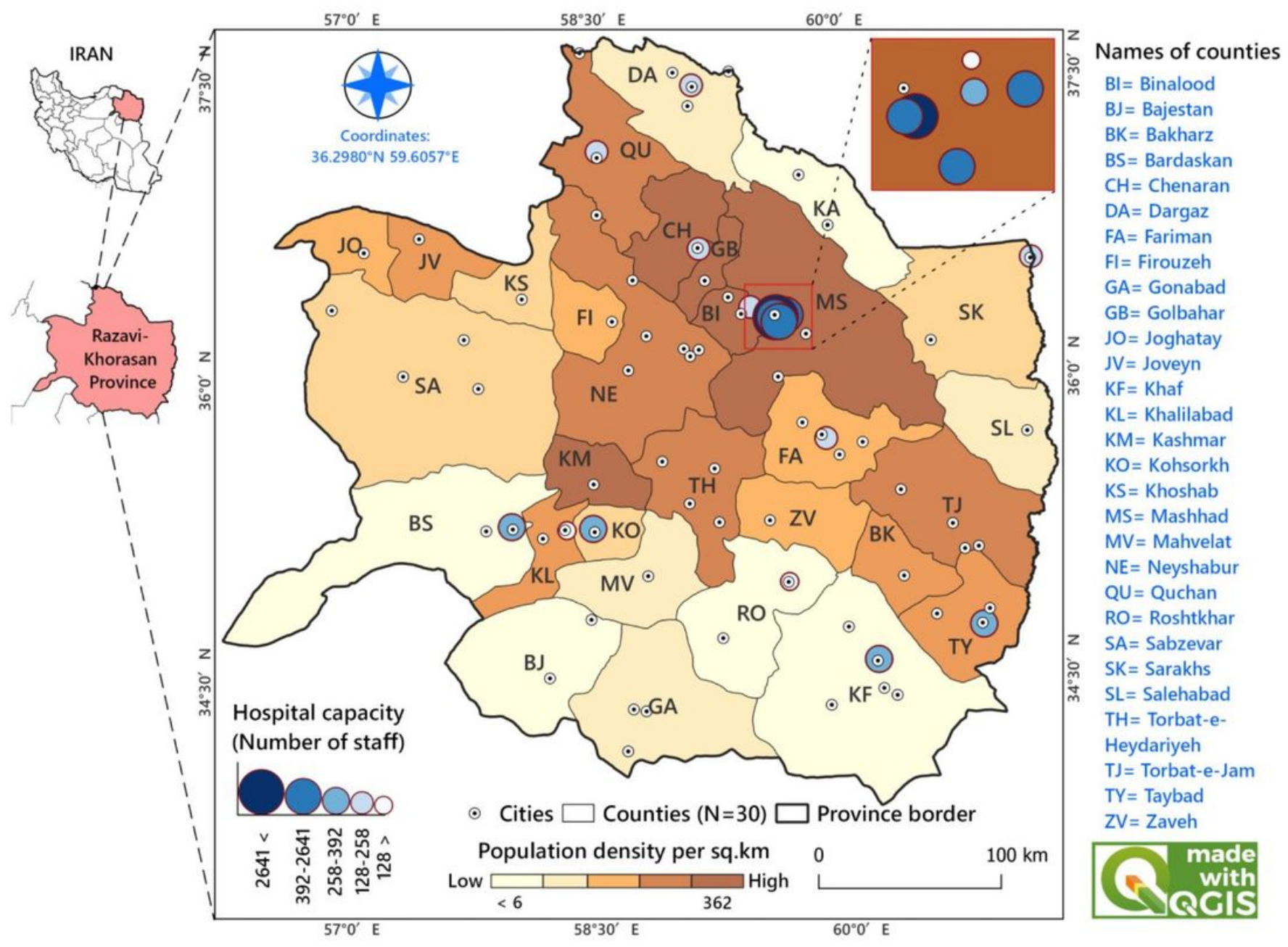

\section{Figure 1}

Map of the study area including hospital capacity and population density of different counties 


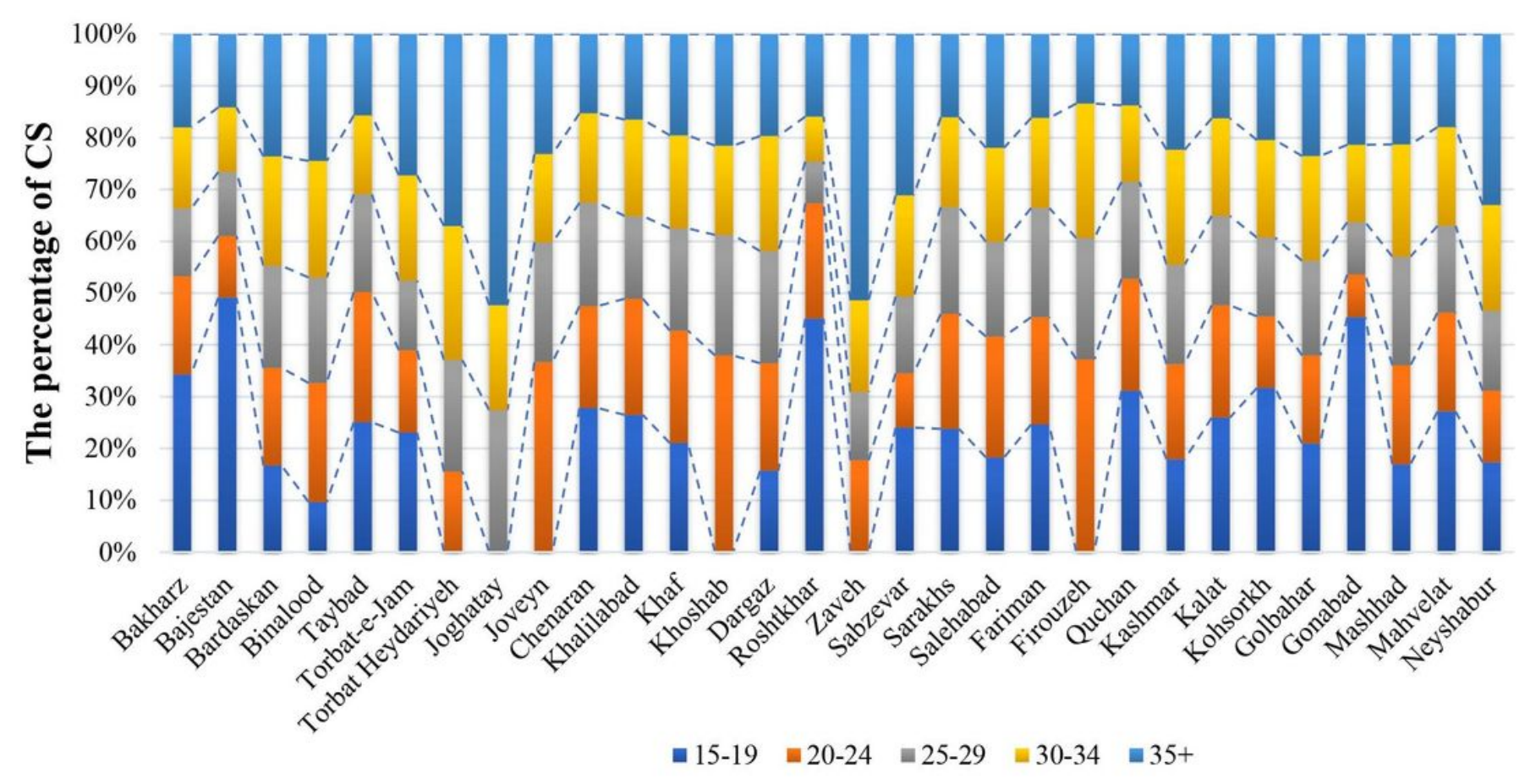

Age Group

Figure 2

The percentage of CS (\%) by county and age groups of mothers 

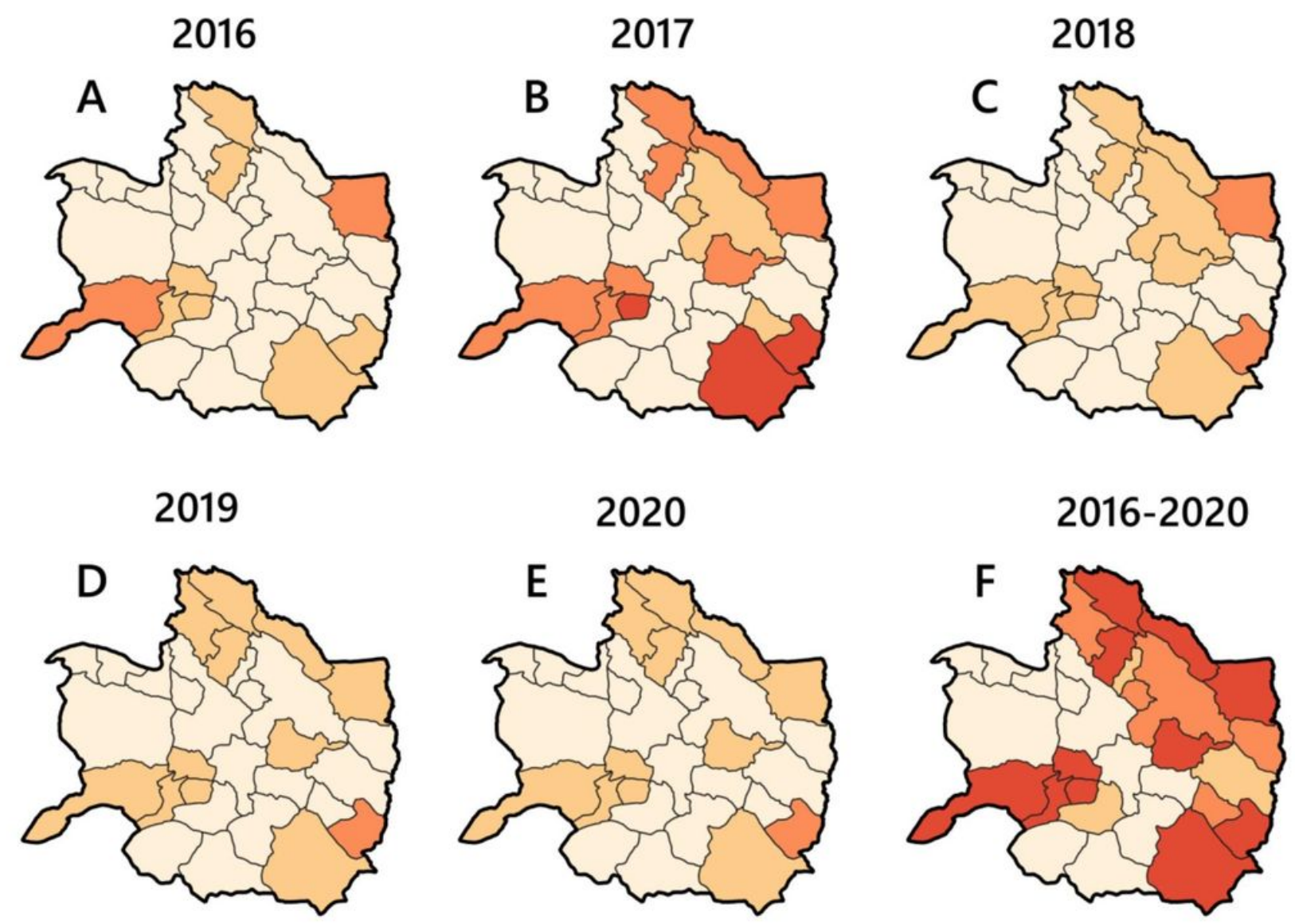

Cesarean-Section EBS rate per 100,000 population

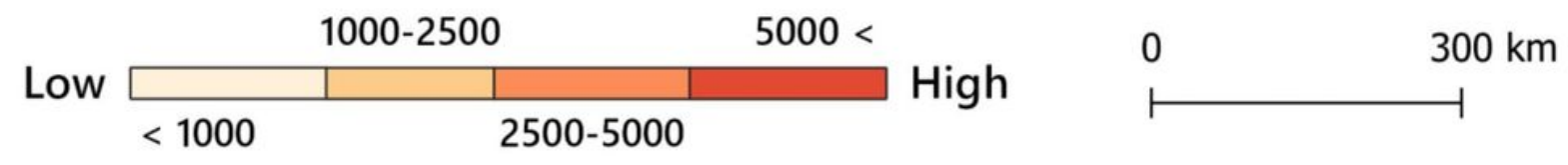

Figure 3

Rate maps of CS deliveries at the county level in KRP, Iran. Dark-red regions represent the highest CS rates, and light-yellow regions represent the lowest CS rates. 


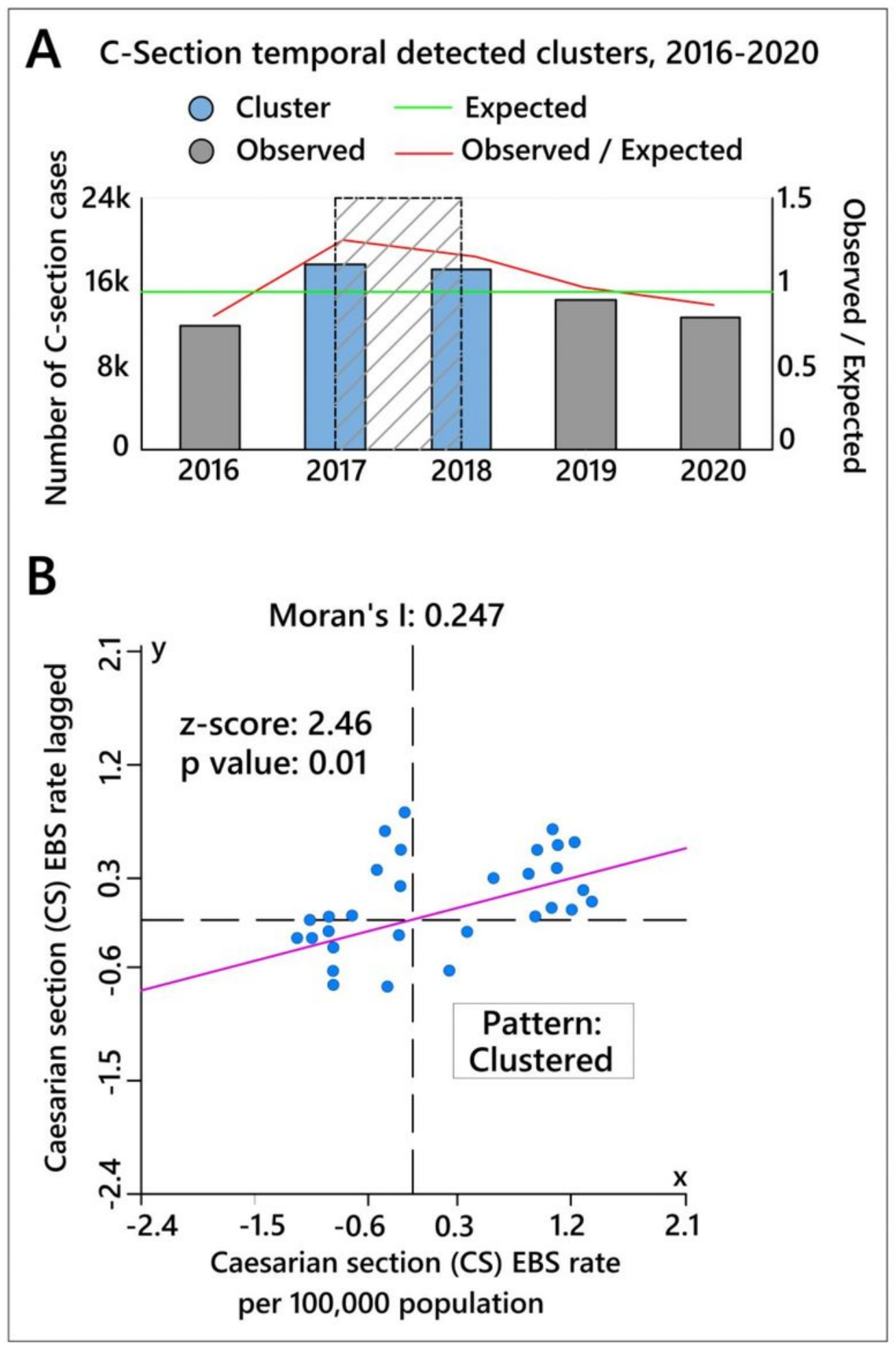

Figure 4

A) Purely temporal clusters identified by $50 \%$ maximum window cluster size in the study region between 2016 and 2020, note: the light blue banded plot area shows significant temporal clusters; B) Global Moran's I statistics for EBS rates of CS deliveries per 100,000 women of childbearing age within the study region from 2016 to 2020. 


\section{Figure 5}

Purely spatial clusters of CS rates identified by the SaTScan approach in the study area

\section{Figure 6}

Spatiotemporal cluster identified by SaTScan approach between 2016 and 2020

\section{Figure 7}

Clusters of spatial variations in temporal trends map

\section{Figure 8}

(A) Closest facility connected to nearest hospitals (red color lines) and expected size of the hospital sphere-of-influence areas (banded by blue color borders). (B) Gravity intensity flows values (red color lines) between origins (counties centroids) and destinations (hospitals).

\section{Figure 9}

(A). The heat map shows the hotspot areas (light yellow) in terms of capacity weighted hospitals per square kilometers. (B) The heat map shows the hotspot areas (light yellow) in terms of normalized gravity intensity of interaction values between origins (counties centroids) and destinations (hospitals). 


\section{Figure 10}

Average distance spent by women for CS delivery in each public hospital in the study area.

Note: symbols $\mathrm{H} 1$ to $\mathrm{H} 18$ indicate the identification number of the health facilities.

\section{Supplementary Files}

This is a list of supplementary files associated with this preprint. Click to download.

- Appendix1.docx 